\begin{abstract}
Alain-Marc Rieu
Professeur émérite, Faculté de philosophie, Université Lyon Jean Moulin

Professeur invite, Osaka University
\end{abstract}

\title{
Building research diversity
}

\author{
Ulrich Hilpert (ed.) \\ Diversities of innovation
}

Cambridge, Routledge, 2019

p 69-82

\section{Beyond the innovation mantra}

The OECD Science, Technology and Industry Scoreboard 2017 proves once again that the solution of last resort to overcome the on-going systemic crisis is to be found in "frontier technology" as the source of industrial innovation. Industrial innovation is supposed to save mature industries, to create new ones, new companies and jobs, which will be paying taxes, which will finance public services, social policies and, in the end, research and innovation policies. The magic circle or virtuous spiral looks, unfortunately, like a steam engine trying to fight its own entropy. What is supposed to happen between this deep source of innovation and the river of growth and welfare remains hidden in a black box. Innovation is our present mantra, used by governments and companies as a magic wand to solve all problems. But magic wands and their gurus explain little. Innovation is foremost a question of practices developed through institutional arrangements associating companies, universities and government. Good practices are not to be found in each of these institutions but in their connections and interactions. These interactions cannot be reduced to any method, which could be copied or taught and then applied. They remain largely informal. So they prove difficult to study in detail and then difficult or impossible to replicate, adapt and adopt. Why some methods and practices are inefficient proves equally difficult to study and explain.

Paradoxically, in such concrete cases, concepts and theories prove extremely useful. They provide a framework in which a goal can be adequately formulated and they also open a 
space for experimentation. In summary, conceptual innovation matters. These concepts are not drawn from nowhere. They carry experience. They are constructed through various conceptual experiments and case studies. Amongst the most powerful and influential conceptual innovations produced in the last thirty years were the National Innovation System model (OECD 1997) of the late 1980s and the Triple Helix model (Etzkowitz and Leydesdorff 1998) of the late 1990s. These two models are closely related, each solving some paradoxes raised by the other. During the present systemic crisis, intensified by growing environmental constraints, intensified debates and research on innovation, new versions of these two models were formulated. ${ }^{1}$ This new research proves the continued heuristic value and its evolutionary potential of these models.

These new circumstances question the established reference point and standard found in Silicon Valley. However successful it might have been, it is neither "a global model, nor a unique anomaly". ${ }^{2}$ It certainly was an inspiration but constructing Silicon Valley into a model to imitate proved a vain exercise and a costly enterprise. Silicon Valley studies led to a more precise understanding of the singular conditions of its emergence and reinvention through time. But the evolution of Silicon Valley since 2000, the burst of the Internet bubble, research trends in the San Francisco Bay area on its future beyond ICT, ${ }^{3}$ doubts also about US long-term competitiveness, create new interests and further research on these models.

In summary, growing environmental constraints and the on-going systemic crisis ${ }^{4}$ have transformed the conditions for research and innovation in all industrial nations. These two models had, and still have, a growing influence at the regional, national and local level. Their interpretations and implementations differ according to contexts. The context matters and makes the difference. Today, in this post-Fukushima context (Rieu 2013), these models need to be redefined by comparing some of their versions. Furthermore, the report by Leydesdorff and Etzkowitz (2003) on the 2002 Triple Helix conference in Copenhagen, 'Can the 'public' be considered as a fourth helix in University-Industry-Government relations?", opened the way

\footnotetext{
${ }^{1}$ For a recent reformulation of the National Innovation System model, see Mariana Mazzucato (2013). The book studies how the state has made, and can still make, a difference while being "entrepreneurial" and "creative".

${ }^{2}$ It was the title of the Triple Helix conference, Stanford, July 2011.

${ }^{3}$ Information and Communication Technology.

${ }^{4}$ When some explain that the crisis is over, it is necessary to indicate that the crisis is systemic because it was first financial in the mid-2007. It became economic and social in 2008, then global and monetary, increasing international tensions and generating regional wars. When the crisis engulfed new industrial nations and energy producers, it generated an increased wave of mass migrations further deconstructing the world order.
} 
for new research on the helix, which is proving particularly relevant. This paper shall further explore this opening and reconfigure the Helix model according to the present context.

\section{The risk of growing standardization}

It is not enough. The real problem is the present systemic crisis. This crisis is often considered to be proof that advanced industrial societies have entered a "secular stagnation" (Summers 2013) or at least a "long-term recession" (Gordon 2010). They cannot expect in the future to repeat the growth rate, which had transformed them since the 19th century, because this high growth was generated by the aggregation of a series of technological discovery. In other words, mature societies should renounce the hope of restoring their historical virtuous spiral or to invent a new one. ${ }^{5}$ The virtuous spiral could only happen once. The reason for the present recession is the high improbability that a new technological wave would generate another, new, long period of growth in industrial societies. The reason is that these countries have reached such a high level of development that a technology, however disruptive, cannot generate a further level of growth so high that it would radically transform the economy, the institutional system and even the culture. Digital technology is certainly a disruptive innovation with deep economic and social consequences, but it did not generate a disruptive growth level.

Theory matters. The notion of "systemic crisis" opens a different perspective. The problem is to question established conceptions of innovation and to focus not on technology but on the institutional environment in which innovation emerges and takes shape within a social system. This is what Science and Technology Studies have been explaining since the 1980s and this is what the twin models are doing. But the present situation requires questioning models, which developed in a different context. Paradoxically, the strong influence of the Triple Helix model leads to a better understanding of its limitations and presuppositions. Explicitly or not, it still inspires research policies and institutional reforms around the world. But its adoption and adaptation have transformed this conceptual construct into an international norm. In the present context, its role as a norm requires opening debates and research because several counter-productive effects are identified or anticipated. For instance, comparing recent research and innovation policies in the European Union and Japan shows which consequences can be observed or predicted with a high degree of probability.

\footnotetext{
5 In a neo-Marxist approach, Wolfgang Streeck (2014), in Buying time. The delayed crisis of democratic capitalism, refuses any sort of prophecy, fate or destiny. He explains the successive policies, which generated and justified at the same the fear of a long-term recession. But innovation is not taken into account. In this paper, I also refuse the prophecy of a long-term recession but try to find a response by extending the concept of innovation.
} 
The first problem is an increased standardization of research. For research and other upstream activities, for universities as well as national and regional research policies, competition has greatly intensified since the 1980s. This competition has been explained and justified by different theories, mainly by Michael Porter's theory of comparative and competitive advantage. But the institutional arrangement at the core of this theory is an Innovation System (national, regional or local) and the operative core of this system is a Triple Helix dispositive. Over time this competition requires an alignment of the competitors, which generates a growing standardization of research and innovation activities. Researchers in advanced industrial societies tend to work in the same fields and on the same themes in institutional environments (organizations, hierarchies, even building design), which have become very similar. The short-term and long-term consequence of this situation is a growing standardization. Competition reinforces this pattern of evolution.

Science might be universal and technology generic, we might observe the emergence of various types of "knowledge economy", in the US and Japan as well as in each Western European nation and at the EU level. Similar attempts in China since 2006, and in Russia or Brazil obviously require deep institutional reforms (including political) to be really successful. ${ }^{6}$ These various types of knowledge economies already compete with each other or intend to compete in the future (Rieu 2008). This intensified competition is reinforcing standardization further. Each nation intends to catch up to narrow the gap with the leader. The leader has to invest resources in order to preserve or reinforce its leadership as the model showing the road to follow. Even if nations competing in science and technology have set historical precedents since the 17th and 19th centuries in Europe, since the birth of modern science, ${ }^{7}$ these are new challenges. Nations do not compete anymore on the basis of their historical differences, of divergent national interests, but to overcome them. Nowadays, at the level of research activities, competition does not oppose nations to each other but makes them converge. Apparently, this convergence reinforces the dominance of the nation, which pretends to be ahead, to be the norm to imitate and reproduce, obviously the United States and within the US, Silicon Valley. But since at least the 1990s, various American think tanks and government agencies have explained how US competitiveness is eroding and why the government should continue to invest more in research and education. The Unites States needs to remain the standard by which others are

\footnotetext{
${ }^{6}$ See my comments (Rieu 2006) in the debate "Inventer une société de la connaissance. Le Japon en comparaison". Ten years later my position is the same concerning China.

${ }^{7}$ See Roger Hahn (1971). The book studies the mimetic rivalry between the Royal Society (1663) and the Paris Academy of science (1666) as well the European-wide consequences of this rivalry on the development of "modern science".
} 
measured in order to sustain their technological hegemony and industrial leadership. Clearly the level of investment to maintain this hegemony is to the detriment of more fruitful and diversified fields of research.

These problems express the mutation of the conception, organization and role of all knowledge activities in advanced industrial societies since the 1980s, the new "regime of knowledge" in which our societies develop and compete. All major research institutions now have the same priorities and objectives. They do not imitate each other but they have entered a mimetic competition, which nobody controls and reinforces its convergent trajectory. The benefits are real: research standardization facilitates the worldwide cooperation of researchers, laboratories and research programs. This convergence even reinforces quality standards and hierarchies, the search for "excellence". But this standardization creates two problems: underneath global and even "open" cooperation, it intensifies competition between laboratories as well as between nations and regions not according to their capacity to generate new research and progress, but to transform this new knowledge into innovations, new industries, new products and services. This situation has obvious positive consequences but the reforms, which can be observed, tend to replicate the model and therefore intensify the mimetic competition further intensifying standardization. From the point of view of the two main challenges, i.e. intensified environmental constraints and a systemic economic crisis, results are below expectations. Innovations in the US or Japan do not generate new disruptive industries, products or jobs. Established conceptions of innovation and research policies do not fully respond to the present conjuncture. It might be a cause, among others, of the so-called "longterm recession".

This situation also has an impact on the other end of the innovation process, on research and research institutions. Because of this cooperation and standardization, where progress really happens in the world is apparently becoming secondary. Few laboratories are making a difference between the progress they really make and the progress they participate in. Laboratories and researchers have the feeling of belonging to a general progress in science and technology. Apparently, researchers develop the same project in different contexts, the climate seems to be the only thing that differs. Graduate and post-graduates circulate between projects looking very similar. This is, of course, an illusion: these similarities hide not only the hierarchy between universities based on the budgets, equipment and selection of researchers, but it hides the institutional contexts in which these laboratories and universities are embedded, their relations to industry, government, society and their respective strategies. The institutional 
context makes the difference. The full extent of this problem is not taken into account, not even identified, neither by governments and civil societies, nor by social scientists who tend to underestimate research and innovation issues. This evolution is obviously reinforced by the need to respond to the present economic and social conjuncture.

Research itself and research institutions are following a potentially dangerous path. This is the second problem: self-reinforcing standardization reduces research and innovation diversity. The reduction of this diversity has a negative impact on research and innovation potentials and therefore on long-term progress. The present growth of research activities intensifies this negative impact at the very moment when advanced industrial societies expect to find the path to their future in scientific progress and technological innovation. In the short term, this standardization does not sterilize research because, as said before, it facilitates the circulation of knowledge and researchers. But reducing research diversity generates a path dependency, which in the long term will tend to sterilize research. These processes are largely invisible and ignored. In summary, it is odd to defend biodiversity and at the same time be blind to the necessity of sustaining and even increasing research diversity.

\section{Innovation in the neoliberal paradigm}

The standardization of research and the reduction of its evolutionary potentials need to be put in a broader perspective. As mentioned before, the convergence of research fields and research organizations brings obvious benefits: it concentrates and aggregates human capital and financial resources. It rationalizes knowledge production and distribution for economic growth and social progress. This convergence is also the result of scientific methodologies and largescale communication of data and research outcomes as well as the result of the increased exchange and circulation of researchers. These positive elements cannot be ignored when humanity is facing increased challenges, deceases, unequal access to food, education and information, energy shortages, industrial pollution and climate change, not to mention security issues. But these positive elements need today to be reinterpreted in a different perspective.

Since the 1980s, this convergence has not only intensified but has also mutated. The first energy and natural resources crisis in 1970s was the initial sign of the emergence of an environmental constraint and the first proof that it would deeply transform our economies, societies and the relations between nations, cultures and territories. Beyond politics and ideology, the neoliberal paradigm and its various practices have been a response since the 1970s to this crisis ( implemented today in order to solve problems generated by these very solutions. In this context, 
a new "regime of knowledge" has emerged and was identified. But its presuppositions and longterm consequences are not yet fully analyzed and evaluated.

The convergence of research fields, of research and innovation models and institutions, is certainly driven by the need to produce new knowledge. But this need is also driven by an intensified competition between economies and societies. The US, Japan and Western European nations have been sharing the same diagnosis of the present world conjuncture and they have, one after the other, implemented a similar response to the globalization process. In the 1990s, it became clear that the long-term future of each advanced industrial societies was to be found in their capacity to generate new knowledge and to translate innovation into new companies and new products, which would create the virtuous circle of growth, jobs, State revenues for financing welfare policies, infrastructures and, of course, research and innovation policies. ${ }^{8}$

In this context, the competition in science and technology between all OECD nations intensified. This new wave of industrial and political competition stimulated all activities related to the production and transfer of knowledge. The main actors of this change were not only managers or politicians; they were scientists, researchers, engineers, even post-doctoral students, and also specialists of recent disciplines like science studies and management of technology. Research policies found a new meaning and a new urgency. Until then, these actors were deeply embedded in social and political systems. Now their interests and values - the logic of their activities - became more openly asserted. Many reforms of research institutions, universities and "national systems of innovation" have been developed since the 1980s. This evolution has its ideology: the formation and management of a "knowledge economy", often taken for a "knowledge society". ${ }^{9}$ This project has different versions: the EU Lisbon strategy, the EU seven Framework programs for Science and Technology and the new Horizon policy as well as Japan's successive Basic plans. Other versions are the various debates, reports and policies in the US concerning competitiveness and innovation. ${ }^{10}$ From this new perspective, Silicon Valley remains a model, but this model is definitely not an overall solution.

The increased standardization resulting from a shared diagnosis and similar responses has reinforced the hegemony of the nation at the source of this process and most advanced in it. As mentioned before, the challenge for the US of sustaining this hegemony dates as far back

\footnotetext{
${ }^{8}$ Concerning Japan, see Rieu (1996).

${ }^{9}$ On the need to draw a distinction between "knowledge economy" and "knowledge society", see Rieu (2005).

${ }^{10}$ See for instance the reports published by the Information Technology and Innovation Foundation (www.itif.org) or the role of innovation in President Obama's 2011 State of the Union speech. He officially converted to the innovation mantra in order to restore or reinvent the golden circle.
} 
as the late 1980s. ${ }^{11}$ When the level of convergence generates standardization of research fields, institutions and policies, beyond quantitative indexes of scientific progress, leadership becomes sheer hegemony. This hegemony generates negative effects and become unsustainable. Today all industrial nations, including China and India, tend to train their scientists and engineers, organize their research institutions and even their territory according to a model developed in the US. Their basic goal is not to produce new knowledge but to catch up, to compete with the United States and reduce the US hegemony or leadership by modernizing their industrial base and creating new industries. This could be accepted by mature and new industrial nations as long as it generated positive effects for all players. But in the face of growing environmental constraints, because of the present systemic crisis, this evolutionary path is counter-productive. In the past, competition through collaboration intensified knowledge creation and innovation. Increasing standardization now reduces research diversity and, in the end, science and technology's productivity.

The concentration of research and training institutions, of expertise, of financial institutions and legal firms required for sustaining or establishing "innovation ecosystems" creates deserts of competence, unequal employment and training opportunities. Not only in China and India but also in the USA or Great Britain. The Triple Helix model developed in this context and it intensifies the counter-productive effects of this evolution. It explains why it needs to be criticized and overcome. It achieved two contradictory tasks. In the context opened in 1980s by the Bayh-Dole Act, it first explained how economic growth required a new institutional arrangement in order to strengthen innovation. Universities were decoupled from public policies and slowly recoupled with business creation and growth. In return, they found new financing resources for research and innovation in this new academic deal. They could grow but they also acquired new responsibilities. Secondly, the Triple Helix model explained how to reach and manage leveraging between government, industry and universities. It provided easy access to enter the black box of innovation. As mentioned in the introduction, nothing is so easy and invoking Silicon Valley as a mantra is not a solution. The Triple Helix belongs to the neoliberal movement, which has revolutionized the world since the 1980s. But it was also regulating the neoliberal revolution by explaining that economic development was based on innovation and that innovation processes were based on collaboration and interaction between

\footnotetext{
${ }^{11}$ The Washington, DC Council on competitiveness was founded in 1986. See www.compete.org. Its reports tell the story of American anxiety of losing the basis of its post-war economic and military hegemony.
} 
university, industry and government. It is part of the problem, not the solution. Its limitations, presuppositions and failures show a path beyond the neoliberal moment.

\section{A fourth helix for building research diversity}

Reversing the trend toward standardization has as its goal the aim of assuring research longterm productivity in the hope of responding to present challenges. The goal is to organize and sustain research diversity. In 2007, Andy Sterling (2007) built a conceptual framework for studying and managing diversity: "Diversity concepts employed across the full range of sciences (...), display some combination of just three basic properties: (...) 'variety', 'balance' and "disparity"'. The variety of research traditions depends on their historical, social, cultural and even economic contexts. But today saving this variety does not mean securing or protecting an imagined historical scientific or technical identity (disparity). It means producing new knowledge and innovating in a world of intensified and mimetic competition. It means stepping out of this competition by developing alternative or simply a variety of perspectives. There is nothing heroic about this. Restoring or creating diversity depends, first of all, on the capacity of academic and research communities to conceive and explicitly debate their own objectives, methods and values with the goal of reaching a "balance" between variety and disparity. Institutional innovation and academic autonomy are key issues in this process. The problem is not to isolate or protect research universities from their economic contexts and social duties. On the contrary, the problem is to give research communities an increased capacity to negotiate their priorities and responsibilities with firms and government.

A Helix model responds to this situation. The problem is: which one? It shows that the "research university" is not submitted to its interactions between firms and government. But it has to assert and play its full role. Institutional innovation does not mean that an "entrepreneurial university" should be organized and managed like a firm. It simply requires stressing the logic of research and innovation, of teaching and training, the various time frames of these activities and their specific institutional requirements. Diversity is a requirement for progress in science and technology as important as standardization. Standardization is a communication requirement while diversity is a requirement for productive and creative investigation. There is no contradiction between the two, but any confusion is negative because it hides the institutional requirements for innovation processes. The individual and collective risk to differ, to develop new fields and hypotheses is a basic duty and responsibility in order to assure long-term research productivity. 
Finally, this implies a different conception of competition. To compete within the same model and for the same objectives is quite different than competing on different grounds and for alternative but also complementary objectives. New modes of collaboration and positive competition can be imagined. Competition is a negative, partial or biased type of collaboration in search of one's own advantage at the expense not only of the other(s) but at the expense of a mutual benefit. Collaborative competition is a key issue. Positive competition does not or should not reduce diversity - but on the contrary - reinforce diversity, intensify global progress and common knowledge. The Helix model is reaching a point where long-term and collective progress should become a goal for all knowledge-based societies.

Therefore, the only way to respond to standardization and negative competition is to build and intensify diversity. This requires exploring the Helix concept and model differently. The most fruitful idea was the introduction of a fourth helix. During the 2002 Triple Helix conference in Copenhagen, the idea was raised to introduce "society" as a fourth helix. Adding this new helix was at first the institutional recognition achieved by Science and Technology Studies and their growing role in policy design. The report on the conference written by Leydesdorff and Etzkowitz (2003), the two originators of the theory, discussed this idea and this discussion opened a new range of debate and research on the Helix theory. But their conclusion was that this idea was redundant because "society is everywhere in the Triple Helix". The problem was, and still is, to establish what "society" really means, or stands for, in a reformed Helix model and theory. In fact, a fourth helix has always been in the middle of the triangle made up of government, universities and firms. But it still is a black box inside a black box.

To give a name and content to this virtual fourth helix has become an urgent question of research and debate. First of all, the fourth helix should not be reduced to "culture", to national traditions because of the historical State control over research activities. To clarify what "society" really means in this context, various answers and experiments exist and they all need to be debated: connecting to civil society, solving social problems, answering social needs, reducing inequities and inequalities, facilitating and taking the point of view of everyday life, bottom up, developing public infrastructure and services, developing skills, creating jobs and employment, establishing a clean and safe environment as well as sustainable social and economic development. Recently the EU Horizon 2020 research, technology and innovation program redefined its foresight methodology and added two new conceptions of this virtual fourth helix. They need to be mentioned because these two officialised fields in Human and 
Social Sciences will be generously funded by Brussels and will draw many answers. The second is a new urgency: "Secure societies-protecting freedom and security of Europe and its citizens". The first one "Europe in a changing world. Inclusive, innovative and reflexive societies" is another conception of a fourth helix. ${ }^{12}$ The collective report The future of Europe states that "the European commission is preparing the funding of grand societal challenges (Burgelman et al. 2015)".

The introduction of a fourth helix transforms the model in many ways beyond the purpose of this paper. The fourth helix has clearly the role of regulating interactions between the three poles of activity and power: universities; government and the State administration; firms, industries and their related services. Industrial property law and technology transfer offices in universities are partly playing this role. Finally, a fourth helix is playing a basic political role outside established political institutions. It regulates the evolution of the whole social system. It reconfigures the relations between politics and technology, research and economics, civil society and research, politics and economics. This mutation was indeed quite predictable, seems irreversible and cannot be opposed by the state apparatus or the business communities: when science and technology concern all aspects of life in society, the way we are educated, work, commute, communicate and even reproduce, a mutation is sooner or later going to take place. All these aspects of life in society first become the target of science and technology policies but they also become the source and inspiration of all these policies. The best experiment was the "social turn" of Japan's $3^{\text {rd }}$ and 4th Basic plans for science and technology, even if the first one was disrupted by the 2008 crisis and the second one by the 2011 Fukushima catastrophe. ${ }^{13}$

This is not enough. The fourth helix needs to receive a practical meaning in order to play its role in relation to universities, government and the economy. It needs to be structured and organized in order "to make sense". In the EU and Japan, making sense is considered an urgent need to prove to "society", to individuals and groups, that research and innovation policies bring visible solutions into the daily life of people, that the benefits are worth the costs of these policies. It is a search for legitimacy. Various solutions are implemented: on-line

\footnotetext{
${ }^{12}$ It will be popular: news from Brussels have explained that this field will be very "open". A strong risk today is not to see "security" becoming one of the "grand societal challenge". The risk is to see "security" becoming a fifth helix, in competition with "society", establishing direct relations with government, industry and universities. Establishing a fourth helix is to assert that "society" is the regulation between the state apparatus, industry and university, that "security" falls within this regulation.

${ }^{13}$ Both plans were unfortunately stalled, the 3 rd one when the 2008 crisis engulfed Japan, the 4 th plan was expected to be launched in April 2011 but the 11 March 2011 catastrophe in Fukushima radically transformed the conditions of its implementation.
} 
surveys in the EU, citizen debates, studies on social needs and social problems, etc. These solutions are difficult to evaluate but obviously further research is needed. To refer to "society" is to indicate the opening of a new or different "public space". Such a public space cannot be reduced to "citizen debates". It is not possible to invoke "society" without referring to the role of human and social sciences. The need to study these issues and problems is a major concern for all these disciplines. The need to disseminate their findings is crucial for society. It is also crucial to reform the formation of scientists and engineers, at all levels, so that they perceive their work not only "from inside out" as they always did, but also "from outside in", from the point of view of society. This social turn of science and technology policy is slowly reorienting research toward different local goals and situated priorities. The energy transition intensifies all these problems and solutions. We also realize that we don't really know anymore what society stands for. But we know at least that this social turn is a turn toward growing diversity.

\section{Irreversibility, risk and democracy}

In 1994, long before the present systemic crisis but during one of its precursors, at the early stage of the globalization process, at a moment when Germany was absorbed by its reunification and unification of two incompatible institutional systems, when Japan's power structure was measuring the full depth of its own crisis, Ulrich Hilpert (1994) was explaining and exploring the paradoxes of the state apparatus, of government and public policies, in their new role and status. It was a decisive moment when different types of policies and theories, highly influential, were designed. ${ }^{14}$ The role of the State was transformed by the neoliberal decoupling of the State, the economy and society as the source of the globalization process. But the task of the state remained essential for establishing the conditions for economic growth and innovation processes. This task had become far more complicated: in this new configuration, political decisions and public policies too often led to unintended and even counter-productive consequences. But the jungle of economic interests was also leading to untended and counterproductive consequences. These unforeseen consequences were obvious at the national level: growing unemployment due to delocalization in low-wage regions, increased inequalities between classes and territories. At the international level, not only mature economies had to face the rapid growth of export economies in East Asia (mainly China) competing with their own industries, but this unequal growth led to an increased marginalization of whole regions in the Middle East and Africa. Whole populations felt and were excluded: they would later re-

\footnotetext{
${ }^{14}$ My paper (Rieu 1996) written for the Japan's National Institute of Research Advancement is a typical example of this conjuncture.
} 
enter history with a vengeance.

In 1994, Ulrich Hilpert and his co-researchers were trying to establish a diagnosis and to find a solution. Their purpose was to overcome these paradoxes and solve these problems by designing new types of regulations and institutional arrangements. The discrepancy between the specific time frames (duration) of political action, firm management and innovation processes, the dynamics of their interactions reshaping contemporary industrial societies in a sort of endless spiral, required a new model. This spiral eventually became a helix. The National innovation system concept and the Helix theory were born in such books and took shape in this context.

Today, Japan is often considered in Europe and North American to be a dragon of the past century. The fact is that Japan was the first nation to find itself-since the end of the 1980s - in the situation, in which other mature industrial societies have found themselves since 2008. The BRICs might have reached this point before having been able to fully take off. The present Chinese administration is trying to escape from a situation it probably considers to be inevitable. So Japan was in the advance and is still a forerunner. I can only provide small hints of Japan's trial and error responses to its long-term crisis. But I explained in some detail the need to escape from the neoliberal mimetic trap by questioning established models and concepts (however recent) of innovation. In summary, social innovation is just as relevant as technological innovation. The urgent problem is a reconstruction of what is commonly called "society". I don't pretend to have any real solutions. I just explained why it is a call for diversity situated at the core of social and economic systems in a different type of research and innovation policy.

This is not playing with words but a serious problem: the intellectual competence and the level of investment required for designing and implementing a relevant research and innovation policy are so high that the resulting orientation is, or nearly is, irreversible. The cost and consequences of epistemic mistakes are so huge that they remain largely invisible. Collective time and funds spent on these policies are not available anymore for exploring other solutions. A trajectory path is created and will last. The best (or worse) example is the case of France with its nuclear policy: French society is in a trap and is unable to escape from it. The costs to escape from the trap and develop an alternative are too high.

The society, which designs such a large-scale policy, is therefore taking an extreme risk. The only solution to manage such a risk is to share it amongst the largest amount of people possible. This political and social technique is called democracy. To involve the largest amount of people is also to reduce this risk as much as possible: it is a call for individual and collective 
intelligence. For those concerned, it requires a high level of competence, experience and/or responsibility. The only solution to manage this situation is to organize such a policy as an experiment in advanced democracy. Citizen debates have become commonplace, but still with mixed results. They are just a forerunner of major political reforms adapted to growing environmental constraints, to comprehensive research and innovation policies and to the transformation of social and economic systems. Understood from the point of view of society, such science and technology policies require new political philosophy and institutions.

\section{References}

Burgelman, J.-C. Chloupkova, J. Wobbe, W. 2015: Foresight in support of European research and innovation policies: The European Commission is preparing the funding of great society challenges. In: Pausch (Ed.): The future of Europe. Springerlink.com.

Etzkowitz, H. and Leydesdorff, L. 1998: The triple helix as a model for innovation studies. In: Science \& Public Policy 25 (3), 195-203.

Gordon, R. 2010: Revisiting U.S. productivity growth over the past century with a view of the future. Working Paper 15834, Cambridge, MA: National Bureau of Economic Research. www.nber.org/papers/w15834.

Hahn, R. 1971: Anatomy of scientific institution: Paris Academy of Science, 1666-1803. Berkeley, CA: University of California Press.

Hilpert, U. (Ed.) 1994: Zwischen Scylla Und Charybdis? Zum Problem Staatlicher Politik Und Nicht-Intendierter Konsequenzen. Wiesbaden: Westdeutscher Verlag.

Leydesdorff, L. and Etzkowitz, H. 2003: Can 'the public' be considered as a fourth helix in university-industry-government relations? Report on the Fourth Triple Helix Conference, 2002, Science and Public Policy 30 (1), 55-61.

Mazzucato, M. 2013: The entrepreneurial state: debunking public vs. private sector myths. London: Anthem. 
OECD. 1997: National innovation systems. Paris: OCDE Publications. https://www.oecd.org/science/inno/2101733.pdf

Rieu, A.-M. 1996: Japan as a techno-scientific society: the new role of research \& development. National Institute for Research Advancement Review, Tokyo, Autumn, 3-6. www.nira.or.jp/past/publ/review/96autumn/rieu.html.

Rieu, A.-M. 2005: What is knowledge society? STS Nexus, San Jose: Santa Clara University, Center for Science, Technology and Society. http://halshs.archives-ouvertes.fr/halshs$\underline{00552293 / \mathrm{fr} /</ \text { URI. }}$.

Rieu, A.-M. 2006. Inventer une société de la connaissance. Le Japon en comparaison. www.diploweb.com/forum/japon07052.htm.

Rieu, A.-M. 2008: Géostratégie de la recherche et de l'innovation. In: Hermès, CNRS Editions 50, 67-73. http://halshs.archives-ouvertes.fr/halshs-00360140/fr/</URI.

Rieu, A.-M. 2012: Beyond neo-liberalism: research policies and society. The case of Japan. In: The Copenhagen Journal of Asian Studies 29 (2), 58-78.

Rieu, A.-M. 2013: Thinking after Fukushima (2). Epistemic shift in human and social science. In: Asia Europe Journal 11 (1), 65-78.

Sterling, A. 2007: A general framework for analyzing diversity in science, technology and society. SPRU online paper 156. www.sussex.ac.uk/spru/</URI. Accessed 9 February.

Streeck, W. 2014: Buying time. The delayed crisis of democratic capitalism. London: Verso.

Summers, L. 2013: www.youtube.com/watch?v=KYpVzBbQIX0</URI. Accessed 8 November. 